\title{
Preparation and identification of an antiserum against recombinant UL31 protein of pseudorabies virus
}

\author{
M. S. CAI ${ }^{1,2}$, S. JIANG ${ }^{1,2}$, C. C. MO ${ }^{1}$, J. L. WANG ${ }^{1}$, J. L. HUANG ${ }^{3}$, Z. C. ZENG ${ }^{1}$, X. W. LI' ${ }^{1}$ Y. J. YANG ${ }^{1}$, C. K. CHEN ${ }^{1}$, \\ W. CUI ${ }^{1}$, M. L. LI $I^{1,2 *}$
}

\begin{abstract}
1.Department of Pathogenic Biology and Immunology, School of Basic Science, Guangzhou Medical University, Guangzhou 510182, P. R. China; ${ }^{2}$ Guangzhou Hoffmann Institute of Immunology, School of Basic Science, Guangzhou Medical University, Guangzhou 510182, P. R. China; ${ }^{3}$ Guangdong Haid Group Co., Ltd., Guangzhou 511400, P. R. China
\end{abstract}

Received November 24, 2014; revised March 26, 2015, accepted July 31, 2015

\begin{abstract}
Summary. - Pseudorabies virus (PRV) late protein UL31 is a homologue of herpes simplex virus 1 (HSV-1) UL31, which is a multifunctional protein important for HSV-1 infection. However, the precise roles of PRV UL31 in virus life cycle are still poorly understood. A relatively crucial tool for uncovering the function of UL31 is an antiserum that specifically detects UL31 in the PRV-infected cells. For this purpose, a recombinant UL31 protein consisting of N-terminal 27 aa of UL31 fused to EYFP and His-tag was expressed, purified and used for the preparation of antiserum in BALB/c mice. Our results show that Western blot analysis and immunofluorescence assay showed that this antiserum could specifically detect the purified recombinant UL31 as well as full-length UL31 in the PRV infected cells. These results demonstrate that the prepared antiserum could serve as a valuable tool for further studies of UL31 functions in PRV infection.
\end{abstract}

Keywords: pseudorabies virus; UL31 protein; recombinant protein; antiserum

\section{Introduction}

Pseudorabies virus (PRV, the genus Varicellovirus, the subfamily Alphaherpesvirinae, the family Herpesviridae) is a pathogen of swine that can cause devastating diseases and economic loss worldwide. PRV is reported to be a useful model for the study of herpesvirus pathogenesis. Furthermore, the neurotropic nature of PRV also makes it a useful tracer of neuronal connections (Pomeranz et al., 2005). Similar to other herpesviruses, PRV genes are believed to be coordinately regulated and expressed at the transcriptional level in a sequential cascade manner and are categorized into

"Corresponding author.E-mail: meili_2011@hotmail.com; phone: 020-37103316. The first four authors contributed equally to this work and each should be considered as a first author.

Abbreviations: HSV-1 = herpes simplex virus 1; IFA = immunofluorescence assay; PRV = pseudorabies virus; p.i. = post infection three kinetic classes: immediate-early, early, and late genes (depending upon the requirements for their transcription and the timing of their synthesis) (Pomeranz et al., 2005).

PRV UL31 protein (encoded by UL31 gene), the homologue of herpes simplex virus 1 (HSV-1) UL31, is the component of the primary tegument with late expression during PRV infection (Granzow et al., 2004). HSV-1 UL31 has been characterized as one of the most important structural protein of HSV-1. Moreover, HSV-1 UL31 has received notable attention thanks to its interaction with HSV-1 UL34 which is involved in several viral replication processes (Ye and Roizman, 2000; Park and Baines, 2006). For example, UL31 and UL34 (i) co-localize at the nuclear rim (Reynolds et al., 2001); (ii) change localization, interaction and phosphorylation of nuclear lamina components and disrupt the nuclear lamina (Reynolds et al., 2004; Simpson-Holley et al., 2004; Klupp et al., 2007); and (iii) facilitate primary encapsidation and nuclear egress of their respective nucleocapsids, which are regulated by the phosphorylation of UL31 with pUS3 (Reynolds et al., 2002; Mou et al., 2009; Roller et al., 2010). Thus, UL31 
is a multifunctional protein. However, the exact function of UL31 during PRV infection is still poorly understood.

In this study, a recombinant prokaryotic plasmid that expresses truncated UL31 protein was constructed; protein was expressed and purified by nickel-nitrilotriacetic $\left(\mathrm{Ni}^{2+}-\right.$ NTA) affinity chromatography. Purified protein was used to raise the polyclonal antiserum in BALB/c mice. Finally, the reactivity and specificity of prepared polyclonal antiserum were characterized by Western blot analysis and immunofluorescence assay (IFA). Prepared antiserum against UL31 has a good reactivity with recombinant and also native UL31.

\section{Materials and Methods}

Medium, enzymes and other materials. DMEM and FBS were purchased from Gibco-BRL. Escherichia coli strains DH5 $\alpha$ and BL21 (DE3) were purchased from Invitrogen. Yeast extract and tryptone for bacterial medium preparation were obtained from Promega. Antibiotics and IPTG were bought from Novagen (USA). DNA polymerase KOD-Plus-Neo was purchased from TOYOBO (Japan). Restriction enzymes, DNA ligase, DNA molecular weight markers and protein molecular weight markers were obtained from TaKaRa. Purification of His-tagged protein was performed on a $\mathrm{Ni}^{2+}$-NTA resin (Qiagen).

Cells. PK-15, HEK293T and Vero cells grown in DMEM were supplemented with $10 \%$ (vol/vol) heat-inactivated FBS, L-glutamine ( $2 \mathrm{mmol} / \mathrm{l})$, penicillin $(100 \mu \mathrm{g} / \mathrm{ml})$, streptomycin $(100 \mathrm{U} / \mathrm{ml})$, essential sodium pyruvate (1\%) and HEPES $(10 \mathrm{mmol} / \mathrm{l})$ and cells were maintained at $37^{\circ} \mathrm{C}$ in $5 \% \mathrm{CO}_{2}$ humidified incubator.

Virus production. PRV-BAC plasmid pBecker2 (Smith and Enquist, 2000) was purified and used for transfection of Vero cells to rescue the virus named vBecker2 as previously described (Li et al., 2011).

Infectious virus assay. To assay infectious virus, the virus was propagated and titered on PK-15 cells as previously described (Li et al., 2011).

Plasmid construction. UL31 ORF was amplified by PCR from PRVBAC pBecker2 with the following primers: UL31-F (5'-CGAAGCTTCGGAATTCATGTTTGAGCGACGGCGGCTC-3') and UL31-R (5'-GCAAGCTTAGGATCCGTCGGGCGAGGGGGGCGAAA-3'). Purified PCR products were digested with EcoRI and BamHI and ligated into the correspondingly digested pEYFP-N1 (Clontech) to generate pUL31-EYFP as in our previous studies (Li et al., 2011). In addition, the DNA fragment encoding N-terminal 27 aa of UL31 amplified from pUL31-EYFP by primers UL31-F and UL31 (1-27)-R (5'TTGGATCCAAGCGATCGCGGGCCGCGCGCG-3') was inserted into pEYFP-N1 to generate pUL31 (1-27)-EYFP. DNA fragment corresponding to the N-terminal 27 aa of UL31 fused to EYFP was digested with EcoRI and NotI and subcloned into the correspondingly digested pET-28a $(+)$ (Novagen) to yield a recombinant prokaryotic expression plasmid pET28a(+)-UL31(1-27)-EYFP. For confirming the presence of the appropriate insert (pET28a(+)-UL31(1-27)EYFP) by PCR, the primer EYFP-R (5'-GAAGATCTCGCTTGTA CAGCTCGTCCATGCCG-3') was used.
Expression and purification of recombinant protein. E. coli BL21 (DE3) were transformed with the recombinant plasmid. The expression and purification of the recombinant protein were performed as described previously (Lin et al., 2010, 2014).

Antiserum preparation. Preimmune serum, which served as a negative control, was collected prior to immunization. Preparation of the antiserum was performed as described previously (Li $e t$ al., 2014). Briefly, BALB/c mice were subcutaneously injected with a mixture of $100 \mu \mathrm{g}$ of purified UL31 recombinant protein mixed with an equal volume of complete Freund's adjuvant (Sigma) on the back and/or proximal limbs. Two weeks later, the mice were boosted twice subcutaneously with the same amount of UL31 recombinant protein mixed with an equal volume of incomplete Freund's adjuvant at a two-week interval. Two weeks after the last immunization, the antiserum was harvested from the sinus orbitalis of $\mathrm{BALB} / \mathrm{c}$ mice and stored at $-80^{\circ} \mathrm{C}$ for further use.

Western blot analysis. Western blot analysis was performed as previously described (Li et al., 2014). Briefly, protein samples were subjected to $10 \%$ SDS-PAGE and transferred electrophoretically to a nitrocellulose membrane by a semi-dry transfer cell (BioRad) at $15 \mathrm{~V}$ for $0.5 \mathrm{hr}$. Membrane was blocked at $37^{\circ} \mathrm{C}$ for $2 \mathrm{hr}$ with $5 \%$ non-fat milk in Tris-buffered saline withTween-20 (TBST, 50 $\mathrm{mmol} / \mathrm{l} \mathrm{Tris-HCl,} 200 \mathrm{mmol} / \mathrm{l} \mathrm{NaCl}, 0.1 \%$ (v/v) Tween-20, $\mathrm{pH} 7.5$ ) and probed with the prepared anti-UL31 antiserum (1:500 dilution) at $37^{\circ} \mathrm{C}$ for $1 \mathrm{hr}$. After washing with TBST, the membrane was incubated with alkaline phosphatase (AP)-conjugated goat anti-mouse IgG (1:10,000 dilution) (Sigma) at $37^{\circ} \mathrm{C}$ for $1 \mathrm{hr}$. Protein bands were developed by 5-bromo-4-chloro-3-indolylphosphate (BCIP)/ nitroblue tetrazolium (NBT) and terminated by distilled water.

Immunofluorescence. To detect the subcellular localization of UL31 in PRV-infected cells, Vero cells were infected with PRV (vBecker2) at an MOI of 1 for 0, 8, 12 and $24 \mathrm{hr}$ and fixed in 4\% paraformaldehyde in phosphate-buffered saline (PBS; $137 \mathrm{mmol} / \mathrm{l} \mathrm{NaCl}, 2.7 \mathrm{mmol} / \mathrm{KCl}$, $10 \mathrm{mmol} / \mathrm{l} \mathrm{Na}_{2} \mathrm{HPO}_{4}$, and $2 \mathrm{mmol} / \mathrm{KH}_{2} \mathrm{PO}_{4}, \mathrm{pH}$ 7.4) for $30 \mathrm{~min}$. After fixation, the cells were blocked with PBS containing 5\% BSA and 10\% FBS for $1 \mathrm{hr}$ at $37^{\circ} \mathrm{C}$. Subsequently, the cells were incubated with UL31specific polyclonal antibody diluted in PBS containing 0.5\% BSA for $1 \mathrm{hr}$ at $37^{\circ} \mathrm{C}$. Finally, fluorescein isothiocyanate (FITC)-conjugated goat anti-mouse immunoglobulin $\mathrm{G}$ (Pierce) was added at a dilution of $1: 200$ and incubated at $37^{\circ} \mathrm{C}$ for $1 \mathrm{hr}$. After each incubation step, the cells were washed extensively with PBS. Hoechst staining was preformed for cell nucleus visualization. Fixed cells were analyzed using a Zeiss Axio Observer A1 microscope (Germany). Images were processed with Adobe Photoshop (Li et al., 2011, 2014).

\section{Results}

Construction of a plasmid expressing recombinant UL31 protein

In an effort to obtain the specific antibody against PRV UL31, which may be used for further investigation of UL31 
biological functions, plasmids pUL31-EYFP and pUL31(1-27) -EYFP were constructed. DNA fragment encoding UL31 (1-27)-EYFP digested with EcoRI and NotI was subcloned from pUL31(1-27)-EYFP into the correspondingly digested pET-28a $(+)$ to produce a recombinant prokaryotic expression plasmid pET28a(+)-UL31(1-27)-EYFP. Subsequently, the recombinant plasmid pET28a(+)-UL31(1-27)-EYFP was verified by colony PCR and restriction analysis. The results showed that it was successfully constructed (data not shown). In addition, DNA sequencing results demonstrated that there was no nucleotide mutation of truncated UL31 protein compared to that of the PRV Becker strain (data not shown).

\section{Expression and purification of recombinant UL31 protein}

After induction with $2.0 \mathrm{mmol} / \mathrm{l} \mathrm{IPTG}$ at $37^{\circ} \mathrm{C}$ for $4 \mathrm{hr}$, E. coli BL21 (DE3) harboring the recombinant plasmid exhibited a high level of expression. A distinct band of approximately $35 \mathrm{~K}$, corresponding to the expected $\mathrm{M}_{\mathrm{r}}$ of recombinant UL31(1-27)-EYFP-His protein, was found only after induction, whereas there was no corresponding protein expression either in BL21 (DE3) harboring pET28a(+) or BL21 (DE3) harboring the recombinant plasmid without IPTG induction (data not shown).

Meanwhile, several expression parameters, including induction by IPTG concentrations and induction times were tested to optimize the expression of the recombinant protein. According to our results, the recombinant protein was found to have high expression under all examined condition (data not shown).

In addition, according to SDS-PAGE analysis of the soluble fraction and cell debris pellet, the induced recombinant protein was found predominantly in the cell debris pellets (data not shown), suggesting that this recombinant protein was mainly insoluble in the form of inclusion bodies.

Purification of the recombinant protein was performed using an immobilized metal affinity chromatography on $\mathrm{Ni}^{2+}$-NTA resin column. SDS-PAGE analysis showed that the recombinant protein was successfully purified and one band corresponding to Mr of about $35 \mathrm{~K}$ was detected (data not shown). Approximately $280 \mathrm{mg}$ of recombinant protein per liter of the culture was obtained after purification. Subsequently, the purified protein was injected into $\mathrm{BALB} / \mathrm{c}$ mice to raise the antiserum.

\section{Characterization of the antiserum against recombinant} UL31 protein

After four immunizations, the antiserum was extracted from sinus orbitalis of $\mathrm{BALB} / \mathrm{c}$ mice. To evaluate the reactivity and specificity of the prepared antiserum we performed Western blot analysis. The antiserum could specifically recognize the purified recombinant protein (Fig. 1, lane 1) and protein in the lysates of BL21 (DE3) harboring the recom-

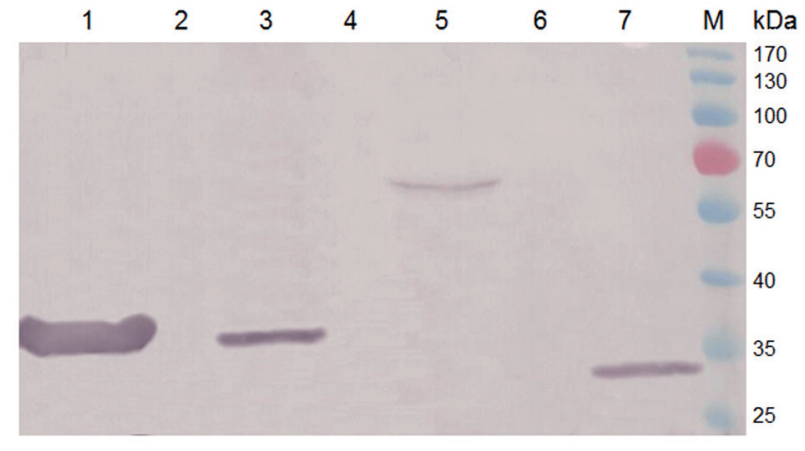

Fig. 1

Characterization of the antiserum against recombinant UL31 protein Western blot analysis of the antiserum. Purified recombinant protein (lane 1); recombinant plasmid in E. coli BL21uninduced (lane 2) and induced (lane 3) with IPTG; untransfected HEK293T cells (lane 4) or HEK293T cells transfected with pUL31-EYFP (lane 5); mock Vero cells (lane 6) and infected with PRV (lane 7); lane M, protein marker.

binant plasmid after induction with $1.0 \mathrm{mmol} / \mathrm{l} \mathrm{IPTG}$ at $37^{\circ} \mathrm{C}$ for $4 \mathrm{hr}$ (Fig. 1, lane 3), but there was no cross-reaction with protein in the lysates of non-transformed BL21 (DE3) (Fig. 1, lane 2) under the same conditions. In addition, Western blot analysis also indicated that the antiserum could clearly detect a band of the EYFP tagged full-length UL31 protein in the lysates of pUL31-EYFP transfected HEK293T cells (Fig. 1, lane 5) whereas no band was observed in the lysates of untransfected HEK293T cells (Fig. 1, lane 4). Moreover, the antiserum was able to recognize UL31 in Vero cells infected with PRV (Fig. 1, lane 7) while no band was detected in mock-infected Vero cells (Fig. 1, lane 6). These results indicate that the prepared antiserum cannot only detect the recombinant UL31 but also the native UL31.

\section{Subcellular localization of UL31 protein in PRV-infected cells}

Thus far we had shown that in Western blot analysis the prepared antiserum could specifically detect UL31 in cells infected with PRV. Here, IFA was carried out to identify the subcellular localization pattern of UL31 in PRV-infected Vero cells at different stages. After 0, 8, 12 and $24 \mathrm{hr}$ post infection (p.i.), PRV-infected Vero cells were fixed and permeabilized. The cells were blocked with BSA to eliminate nonspecific binding and incubated with the prepared antiserum. As shown in Fig. 2, UL31 was distributed throughout the nucleus after $8 \mathrm{hr}$ p.i., and after $24 \mathrm{hr}$ p.i. It was localized predominantly at nuclear rim or nuclear membrane. In contrast, no specific staining was observed in PRV-infected cells 0 hr p.i. (Fig. 2). These results suggest that the prepared antiserum against the recombinant protein has a good reactivity and specificity against the native UL31 protein in infected cells, and also reveals that UL31 is a nuclear-targeted protein. 


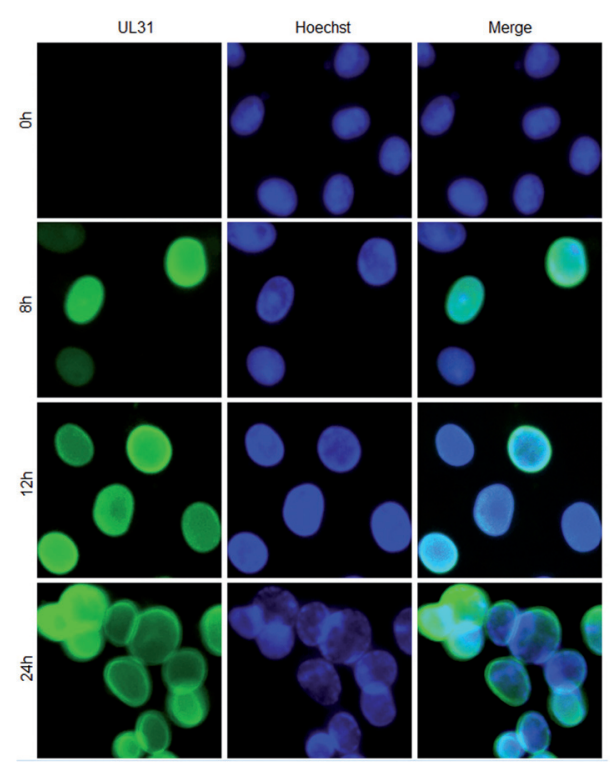

Fig. 2

Subcellular localization of the UL31 protein in PRV-infected Vero cells

Immunofluorescence of cells infected with PRV vBecker2 at an MOI of 1 , after $0,8,12$ and $24 \mathrm{hr}$ p.i. with the antiserum against the recombinant UL31 protein.

\section{Discussion}

Here we raised an antiserum against the recombinant UL31 protein which could specifically recognize the full-length UL31 protein. To establish an efficient approach to purify the recombinant UL31, a $\mathrm{Ni}^{2+}$-NTA resin column, which exhibits a high binding capacity allowing for a very rapid and singlestep purification, was applied to purify the recombinant UL31 protein (Arnau et al., 2006). Additionally, GFP or its mutant has been already used as probe to detect protein expressed in live cells, therefore, truncated UL31 protein was tagged with EYFP in this study (Chalfie et al., 1994). Furthermore, for the expression of recombinant UL31 protein, the E. coli strain BL21 (DE3) was used. This strain has the advantage of being deficient in both the lon and ompT proteases and harbors the T7 bacteriophage RNA polymerase gene, which permits the specific expression of heterologous genes driven by the T7 promoter (Studier et al., 1990; Mierendorf et al., 1998).

It is well known that diverse intracellular localizations might reflect different roles of viral proteins, and the intracellular localization of viral proteins may also vary at different times after infection (Feng, 2002). For instance, it has been shown that the localization of HSV-1 UL31 can re-locate from the nucleus to small dense nuclear bodies during the viral replication cycle in Vero cells infected with HSV-1 (Lin et al., 2010), and PRV UL54 relocated from nucleolus to the nucleus as the virus replicates in PK-15 cells at low MOI (Li et al., 2011, 2012). Thus, using the prepared antiserum, the subcellular localization of UL31 in PRV-infected Vero cells was observed at various times post infection. The results showed that after $8 \mathrm{hr}$ p.i. UL31 mainly localized in the nucleus of Vero cells infected with PRV, however, later during the infection, UL31 redistributed from nucleus to the nuclear membrane. It was reported that UL31 and UL34 are required for nuclear egress of herpesviruses from all three subfamilies. UL34 is targeted to the nuclear envelope even in the absence of other viral proteins, whereas UL31 is found diffusely distributed in the nucleus in transfected cells but is relocated to the nuclear rim in the presence of UL34 (Reynolds et al., 2001, 2002, 2004; Fuchs et al., 2002; Simpson-Holley et al., 2004; Klupp et al., 2007; Mou et al., 2009; Roller et al., 2010). Besides, HSV-1 UL31 and UL34 have separate but related functions in recruiting appropriate components to nucleocapsid budding sites at the inner nuclear membrane (Wills et al., 2009). Furthermore, HSV-1 UL31 might form a network to enable the anchorage of viral products for the synthesis and/or packaging of viral DNA into virions (Chang et al., 1997). Moreover, HSV-1 UL31 is also implicated in the optimal activation of NF- $\mathrm{kB}$ and expression of viral gene products (which are frequently related with the nucleus) (Roberts and Baines, 2011), it is therefore not unexpected that UL31 is a primarily nuclear associated protein.

Taken together, the antiserum raised against the recombinant UL31 could recognize not only the purified UL31 but also the native UL31 in PRV-infected cells. Accordingly, this antiserum may serve as a valuable tool for further study of the biological functions of UL31 during PRV infection.

Acknowledgements. This work was supported by grants from the National Natural Science Foundation of China (31200120 and 31400150); the Natural Science Foundation of Guangdong Province (S2013040016596 and 2015A030313473); the Foundation for Distinguished Young Talents in Higher Education of Guangdong, China (2013LYM_0096); the Pearl River S\&T Nova Program of Guangzhou (2013J2200018); the Science and Technology Program of Guangzhou, China (201504291022514);the Scientific Research Projects in Colleges and Universities of Guangzhou (1201430024); the Scientific Research Foundation for the Ph.D., Guangzhou Medical University (2014C02); the Medical Scientific Research Foundation of Guangdong Province, China (B2012165); the First Batch of Young Core Instructor of Guangzhou Medical University; the Thousand Hundred Ten Projects of Guangzhou Medical University, Guangdong; National Undergraduate Training Programs for Innovation and Entrepreneurship (201510570006); and the Students' extracurricular scientific and technological activities in Guangzhou Medical University (2014005). The authors thank Dr. Lynn W. Enquist for the generous gift of pBecker2.

\section{References}

Arnau J, Lauritzen C, Petersen GE, Pedersen J (2006): Current strategies for the use of affinity tags and tag removal for the purification of recombinant proteins. Protein Expr. Purif. 48, 1-13. http://dx.doi.org/10.1016/j.pep.2005.12.002 
Chalfie M, Tu Y, Euskirchen G, Ward WW, Prasher DC (1994): Green fluorescent protein as a marker for gene expression. Science 263, 802-805. http://dx.doi.org/10.1126/ science. 8303295

Chang YE, Van Sant C, Krug PW, Sears AE, Roizman B (1997): The null mutant of the $\mathrm{U}(\mathrm{L}) 31$ gene of herpes simplex virus 1: construction and phenotype in infected cells. J. Virol. 71, 8307-8315.

Feng ZP (2002): An overview on predicting the subcellular location of a protein. In Silico Biol. 2, 291-303.

Fuchs W, Klupp BG, Granzow H, Osterrieder N, Mettenleiter TC (2002): The interacting UL31 and UL34 gene products of pseudorabies virus are involved in egress from the host-cell nucleus and represent components of primary enveloped but not mature virions. J. Virol. 76, 364-378. http://dx.doi.org/10.1128/JVI.76.1.364-378.2002

Granzow H, Klupp BG, Mettenleiter TC (2004): The pseudorabies virus US3 protein is a component of primary and of mature virions. J. Virol. 78, 1314-1323. http://dx.doi. org/10.1128/JVI.78.3.1314-1323.2004

Klupp BG, Granzow H, Fuchs W, Keil GM, Finke S, Mettenleiter TC (2007): Vesicle formation from the nuclear membrane is induced by coexpression of two conserved herpesvirus proteins. Proc. Natl. Acad. Sci. USA 104, 7241-7246. http://dx.doi.org/10.1073/pnas.0701757104

Li ML, Cui W, Mo CC, Wang JL, Zhao ZY, Cai MS (2014): Cloning, expression, purification, antiserum preparation and its characteristics of the truncated UL6 protein of herpes simplex virus 1. Mol. Biol. Rep. 41, 5997-6002. http:// dx.doi.org/10.1007/s11033-014-3477-y

Li ML, Li Z, Li WT, Wang BY, Ma CQ, Chen JH, Cai MS (2012): Preparation and characterization of an antiserum against truncated UL54 protein of pseudorabies virus. Acta Virol. 56, 315-322. http://dx.doi.org/10.4149/ av $2012 \quad 04 \quad 315$

Li ML, Wang S, Cai MS, Zheng CF (2011): Identification of nuclear and nucleolar localization signals of pseudorabies virus (PRV) early protein UL54 reveals that its nuclear targeting is required for efficient production of PRV. J. Virol. 85, 10239-10251. http://dx.doi.org/10.1128/JVI.05223-11

Lin F, Ren X, Guo H, Ding Q, Zheng AC (2010): Expression, purification of the UL3 protein of herpes simplex virus type 1, and production of UL3 polyclonal antibody. J Virol. Methods 166, 72-76. http://dx.doi.org/10.1016/j. jviromet.2010.02.022

Mierendorf RC, Morris BB, Hammer B, Novy RE (1998): Expression and Purification of Recombinant Proteins Using the pET System. Methods Mol. Med. 13, 257-292.

Mou F, Wills E, Baines JD (2009): Phosphorylation of the U(L)31 protein of herpes simplex virus 1 by the $\mathrm{U}(\mathrm{S}) 3$-encoded kinase regulates localization of the nuclear envelopment complex and egress of nucleocapsids. J. Virol. 83, 5181-5191. http://dx.doi.org/10.1128/JVI.00090-09

Park R, Baines JD (2006): Herpes simplex virus type 1 infection induces activation and recruitment of protein kinase $\mathrm{C}$ to the nuclear membrane and increased phosphorylation of lamin B. J. Virol. 80, 494-504. http://dx.doi.org/10.1128/ JVI.80.1.494-504.2006

Pomeranz LE, Reynolds AE, Hengartner CJ (2005): Molecular biology of pseudorabies virus: impact on neurovirology and veterinary medicine. Microbiol. Mol. Biol. Rev. 69, 462-500. http://dx.doi.org/10.1128/MMBR.69.3.462500.2005

Reynolds AE, Liang L, Baines JD (2004): Conformational changes in the nuclear lamina induced by herpes simplex virus type 1 require genes $\mathrm{U}(\mathrm{L}) 31$ and $\mathrm{U}(\mathrm{L}) 34$. J. Virol. 78, 5564-5575. http://dx.doi.org/10.1128/JVI.78.11.5564-5575.2004

Reynolds AE, Ryckman BJ, Baines JD, Zhou Y, Liang L, Roller RJ (2001): U(L)31 and $\mathrm{U}(\mathrm{L}) 34$ proteins of herpes simplex virus type 1 form a complex that accumulates at the nuclear rim and is required for envelopment of nucleocapsids. J. Virol. 75, 8803-8817. http://dx.doi.org/10.1128/ JVI.75.18.8803-8817.2001

Reynolds AE, Wills EG, Roller RJ, Ryckman BJ, Baines JD (2002): Ultrastructural localization of the herpes simplex virus type 1 UL31, UL34, and US3 proteins suggests specific roles in primary envelopment and egress of nucleocapsids. J. Virol. 76, 8939-8952. http://dx.doi.org/10.1128/ JVI.76.17.8939-8952.2002

Roberts KL, Baines JD (2011): UL31 of herpes simplex virus 1 is necessary for optimal NF-kappaB activation and expression of viral gene products. J. Virol. 85, 4947-4953. http:// dx.doi.org/10.1128/JVI.00068-11

Roller RJ, Bjerke SL, Haugo AC, Hanson S (2010): Analysis of a charge cluster mutation of herpes simplex virus type 1 UL34 and its extragenic suppressor suggests a novel interaction between pUL34 and pUL31 that is necessary for membrane curvature around capsids. J. Virol. 84, 3921-3934. http://dx.doi.org/10.1128/JVI.01638-09

Simpson-Holley M, Baines J, Roller R, Knipe DM (2004): Herpes simplex virus $1 \mathrm{U}(\mathrm{L}) 31$ and $\mathrm{U}(\mathrm{L}) 34$ gene products promote the late maturation of viral replication compartments to the nuclear periphery. J. Virol. 78, 5591-5600. http://dx.doi.org/10.1128/JVI.78.11.5591-5600.2004

Smith GA, Enquist LW (2000): A self-recombining bacterial artificial chromosome and its application for analysis of herpesvirus pathogenesis. Proc. Natl. Acad. Sci. USA 97, 4873-4878. http://dx.doi.org/10.1073/pnas.080502497

Studier FW, Rosenberg AH, Dunn JJ, Dubendorff JW (1990): Use of T7 RNA polymerase to direct expression of cloned genes. Methods Enzymol. 185, 60-89. http://dx.doi. org/10.1016/0076-6879(90)85008-C

Wills E, Mou F, Baines JD (2009): The U(L)31 and U(L)34 gene products of herpes simplex virus 1 are required for optimal localization of viral glycoproteins $\mathrm{D}$ and $\mathrm{M}$ to the inner nuclear membranes of infected cells. J. Virol. 83, 4800-4809. http://dx.doi.org/10.1128/JVI.02431-08

Ye GJ, Roizman B (2000): The essential protein encoded by the UL31 gene of herpes simplex virus 1 depends for its stability on the presence of UL34 protein. Proc. Natl. Acad. Sci. USA 97, 11002-11007. http://dx.doi.org/10.1073/ pnas.97.20.11002 